\title{
El anclaje de la renovación urbana: conjunto urbano Paseo Molino en el Centro Histórico de la ciudad de Toluca, México
}

\author{
Anchoring of urban renewal: Urban complex Paseo Molino in the Historic Center of the city of Toluca, Mexico
}

\section{Silvia Valencia Flores}

Universidad Autónoma del Estado de México, Toluca, México.

silvia181081@hotmail.com

\section{María Estela Orozco Hernández}

Universidad Autónoma del Estado de México, Toluca, México.

\section{Jorge Tapia Quevedo}

Universidad Autónoma del Estado de México, Toluca, México.

\section{Teresa Becerril Sánchez}

Universidad Autónoma del Estado de México, Toluca, México.

\section{Resumen}

Actualmente en los centros históricos de las ciudades mexicanas convergen tendencias modernizantes expresadas en su forma física, actividades comerciales y tensiones sociales. El artículo analiza el anclaje de la renovación urbana en el centro histórico de la ciudad de Toluca, a través del conjunto Paseo Molino, el cual marca un hito en la producción de vivienda vertical, comercios y servicios en un sector que desconoce antecedentes semejantes. Por medio de entrevistas semiestructuradas y recorridos exploratorios, se caracteriza el entorno urbano del proyecto, los agentes y mecanismos de la apropiación del suelo urbano y la prospectiva de los impactos esperados. El anclaje urbano expresa niveles de intervención y grados de decisión pública y privada que configuran un modo distinto de gestión urbana a través de la intensificación del uso urbano y mecanismos que instituyen el fideicomiso para garantizar la rentabilidad. Se concluye en la importancia del reacomodo de las relaciones gobierno y sector privado para enfrentar la continuidad del pasado que se remonta a casi dos siglos, y que en lo sucesivo constituirá un factor que podría frenar la multiplicación de modernas intervenciones urbanísticas en el centro histórico de la ciudad de Toluca.

Palabras clave: centro histórico, conjunto urbano, intervención urbanística, renovación urbana.

\begin{abstract}
Currently in the historical centers of the Mexican cities converge modernizing tendencies expressed in their physical form, commercial activities and social tensions. The article analyzes the anchoring of urban renewal in the historic center of the city of Toluca, through the Paseo Molino complex, which marks a milestone in the production of vertical housing, shops and services in a sector that does not know similar backgrounds. Through semi-structured interviews and exploratory tours, the urban environment of the project, the agents and mechanisms of the appropriation of urban land and the prospective of the expected impacts are characterized. The urban anchor expresses levels of intervention and degrees of public and private decision that configure a different mode of urban management through the intensification of urban use and mechanisms that establish the trust to guarantee profitability. It concludes in the importance of the rearrangement of government and private sector relations to face the continuity of the past that goes back almost two centuries, and which will henceforth constitute a factor that could curb the multiplication of modern urban interventions in the historic center of the city of Toluca.
\end{abstract}

Keywords: historical center, urban complex, urban intervention, urban renewal.

Documento recibido el 27 de marzo de 2018 y aceptado el 20 de septiembre de 2019.

Cómo citar: Valencia Flores, S., Orozco Hernández, M. E., Tapia Quevedo, J. y Becerril Sánchez, T. (2019). El anclaje de la renovación urbana: conjunto urbano Paseo Molino en el Centro Histórico de la ciudad de Toluca, México. Revista de Urbanismo, 41, 1-17. https://doi.org/10.5354/0717-5051.2019.48807 


\section{Introducción}

La controversia ciudad inclusiva (Balbo, Jordán y Simioni, 2003) y ciudad segmentada (Alfonso, 2005), confronta la ciudad para todos y la ciudad que emerge de la reestructuración de la economía global. La reestructuración del sistema productivo, la internacionalización del espacio y las relaciones, las modificaciones sociopolíticas, la concentración del poder, los nuevos procesos de acumulación capitalista y las modernas tecnologías componen el escenario donde las ciudades se insertan. La inserción en el circuito mundial de acumulación del capital está cambiando la morfología de las grandes urbes (De Mattos, Riffo, Yáñez y Salas, 2004; Sassen, 1991; Soja, 2004). La reorganización espacial del capital (Tapia Blanco, 2013) y la actuación de los gobernantes, determina un modo propio de organizar cada ciudad (Rossi, 2013).

Los gobiernos nacionales se ocupan de la creación de los entornos propicios para el desarrollo competitivo de las ciudades, atraer inversiones y retenerlas (Cabrero, 2009). Una de las estrategias es reactivar áreas que han perdido funcionalidad (Hernández, 2014). Este es el caso de los centros históricos, los cuales caracterizan la decadencia de las funciones económicas y sociales de las áreas urbanas centrales (Soja, 2004). En la perspectiva de la urbanización de lo urbano (Falú y Marengo, 2004), o la vuelta a la urbe construida, "los centros históricos tienen nuevos retos vinculados a las accesibilidades, a las centralidades intraurbanas, a las simbologías existentes y las tramas de relaciones que les dan sustento" (Carrión, 2003, p.129).

La reactivación de los centros históricos redimensiona su localización, alto valor de situación y accesibilidad, estas cualidades constituyen soportes básicos para arbitrar nuevas fórmulas de promoción urbana, mediante políticas y estrategias tendentes a mejorar las condiciones físicas de este sector de la ciudad, programas de reciclaje y renovación urbana, transformándolos en lugares atractivos (Polése, 1998; Hurtado, 2011).

A través de las alianzas entre inversionistas y gobiernos emergen proyectos que se materializan en edificaciones dirigidas a sectores de consumidores que cuentan con poder adquisitivo para adquirir una vivienda o departamento. Las políticas públicas trasmutan el concepto de ciudadanía al de consumidor, limitando la accesibilidad a la capacidad de consumo y coadyuvando en la reapropiación privada del suelo urbano (Valencia, 2004 , p.22,31), lo que anticipa impactos de largo plazo en la historia urbana (Zunino, 2000).

Los antecedentes de las estrategias de intervención urbanística inherentes a la función pública remontan a las crisis de la primera y segunda posguerra, entonces la reconstrucción de las ciudades se caracterizó por expropiaciones, demolición de edificios y vivienda degradada, acciones de rehabilitación y renovación urbana. Hasta los años ochenta en las ciudades europeas la renovación urbana se concebía como intervenciones agresivas mediante la demolición y causa del desplazamiento de residentes. las críticas y los movimientos sociales detonaron cambios en las políticas en favor del modelo integral para hacer ciudad (Campesino, 1989).

En la actualidad, en algunos países latinoamericanos con fuerte influencia europea, la renovación urbana se reconoce como una estrategia de demolición de barrios degradados para edificar nuevas áreas urbanas y como factor que propicia el desplazamiento social. El estudio de las estrategias urbanísticas y sus efectos en ciudades de América Latina han acuñado términos diversos, entre ellos; rehabilitación (Goulart, 2005; Sánchez López, 2000); refuncionalización (Gioria, 2003), revitalización (Quintana, 1999; Goulart, 2005), recuperación urbana (Tamarit, 2001) y renovación urbana (Goulart, 2005, Vite Pérez, 2010) (Tabla 1). 


\section{Tabla 1}

Síntesis de las estrategias urbanisticas

\begin{tabular}{|c|c|c|c|c|}
\hline \multirow[t]{2}{*}{ AUTOR } & \multirow[t]{2}{*}{ Intervención } & \multicolumn{3}{|c|}{ Aspectos } \\
\hline & & Morfológico & Social & Económico \\
\hline 1 & $\begin{array}{l}\text { Demolición de edificios } \\
\text { preexistentes }\end{array}$ & $\begin{array}{l}\text { Construcción de nuevas } \\
\text { edificaciones y cambio en de } \\
\text { paisaje urbano }\end{array}$ & Desplazamiento de residentes & Especulación inmobiliaria \\
\hline II & Densificación urbana & $\begin{array}{l}\text { Construcción de vivienda en } \\
\text { altura, cambio del paisaje } \\
\text { urbano }\end{array}$ & $\begin{array}{l}\text { Retorno al centro, atracción de } \\
\text { nuevos residentes, migración } \\
\text { intraurbana y cambio del tejido } \\
\text { social }\end{array}$ & Sustitución de usos y funciones \\
\hline III & $\begin{array}{l}\text { Rehabilitación de inmuebles } \\
\text { residenciales para uso } \\
\text { comercial }\end{array}$ & $\begin{array}{l}\text { Mejoramiento de la imagen } \\
\text { urbana (boutiquización) }\end{array}$ & $\begin{array}{l}\text { Pérdida sustancial de } \\
\text { población, cambio demográfico } \\
\text { y socioeconómico }\end{array}$ & $\begin{array}{l}\text { Aumento de inversión privada y el } \\
\text { precio de suelo }\end{array}$ \\
\hline IV & $\begin{array}{l}\text { Rehabilitación de vivienda y } \\
\text { barrios degradados }\end{array}$ & $\begin{array}{l}\text { Nuevos equipamientos y } \\
\text { actividades terciarias }\end{array}$ & $\begin{array}{l}\text { Expulsión de población de } \\
\text { bajos recursos }\end{array}$ & $\begin{array}{l}\text { Localización de nuevos comercios } \\
\text { Y sustitución de usos y funciones }\end{array}$ \\
\hline $\mathbf{v}$ & $\begin{array}{l}\text { Reconversión del borde } \\
\text { costero, al ocio nocturno }\end{array}$ & $\begin{array}{l}\text { Cambios de uso del suelo y } \\
\text { transformación del paisaje } \\
\text { urbano }\end{array}$ & $\begin{array}{l}\text { Expulsión de habitantes de } \\
\text { bajos ingresos. }\end{array}$ & Aumento del precio de suelo \\
\hline & & & & Sustitución de usos y funciones \\
\hline VI & $\begin{array}{l}\text { Reconversión de áreas } \\
\text { industriales }\end{array}$ & $\begin{array}{l}\text { Nuevos equipamientos y } \\
\text { espacios públicos }\end{array}$ & $\begin{array}{l}\text { Espacios de convivencia } \\
\text { colectiva }\end{array}$ & Sustitución de usos y funciones \\
\hline
\end{tabular}

Elaboración propia, con base en. I. Brunet, 1993. II. Herce, 2005; López Morales, 2008; Rodríguez,2007. III. Carrión, 2010, Contreras, 2011; Sandroni, 2006. IV. Martínez, 2004. V. Kanai \& Ortega, 2009; Lacarrieu, Thomaz, Yacovino, Lekerman y Crovara, 2011; Nobre, 2002; Ormindo de Azevedo, 2009; Schelotto, 2007; Vergara, 2013. VI. Martínez, 2004.

Las estrategias urbanísticas no son excluyentes, tienen en común la connotación morfológica, social y económica y la urgencia de los gobiernos por allegarse de ingresos en distintos contextos geográficos, lo que enmarca la revitalización económica y la renovación urbana de las áreas centrales como aspectos estratégicos de las políticas públicas. Cada caso es distinto, sin embargo, a través de la intervención urbanística se potencializa la inversión pública y privada en sectores y sitios específicos de la ciudad o región de que se trate, y se reactivan los usos urbanos y las funciones económicas.

En los centros históricos, los edificios y monumentos narran las huellas que ha dejado en ellos el tiempo; son lugares degradados con movilidad difícil y baja calidad de vida, y no son atractivos para vivir, al mismo tiempo contienen lugares y elementos originales propios (Vinuesa, 1992). Todos aquellos elementos que la gestión pública y privada convierte en potentes y diversificados focos de atracción, por las expectativas de su rentabilidad económica. La revalorización de los barrios degradados centrales es posible si el sector público asume el coste del contagio privado y sustituye el funcionamiento del mercado por una mezcla de inversiones públicas $y$ privadas. Las subvenciones del gobierno minimizan los costes para los ayuntamientos y la construcción de inmuebles nuevos supone aumento de los ingresos fiscales de la administración local. Los gobiernos asumen el papel de gerente, cuyo enfoque político-electoral, cambia al enfoque territorial-gremial, las decisiones se rigen por un modelo de gestión empresarial descentralizado, que norma a la ciudad como un mercado para solucionar la crisis urbana (Richardson, 1971).

Las estrategias de intervención urbanística se aplican como solución de marketing político y aprovechamiento de plusvalías, para convertir espacios vacantes o deteriorados en áreas de prestigio (Precedo, 1996, pp.2931), mediante la rehabilitación de fachadas e inmuebles de valor patrimonial e histórico; recuperación de espacios vacíos, vacantes y subutilizados. Los servicios y equipamiento urbano, subvencionado por los gobiernos, abaten costos para incorporar barrios degradados al mercado de bienes y servicios. La renovación urbana se realiza en sitios precisos de la estructura urbana, aquellos que tienen potencial para hacer un lugar atractivo para la población (Hurtado, 2011, p.5). Las mayores asignaciones de capital al suelo se encuentran en el centro de la ciudad 
y allí se tienen los máximos movimientos positivos de los precios del suelo, las firmas inmobiliarias harán uso intensivo de los factores no suelo, los cuales se reflejarán en la mayor altura de las edificaciones. La verticalización evidencia procesos de renovación urbana en los que el suelo es sometido a una mayor intensidad de uso. El suelo producido para las capas medias de la población, interioriza estacionamientos privados, salones comunales o gimnasios. Las cesiones de suelo que se pagan por la mezcla de usos valorizan el tiempo de trabajo de los usuarios y son elementos diferenciadores de la estructura socio espacial urbana. La capacidad de apropiarse (material o simbólicamente) de bienes (públicos o privados), depende del capital que se posee, esto se manifestará en la producción de espacio edificado, que sienta bases materiales para la segmentación residencial y la exclusión económica derivada del diferencial de rentas que las familias poseen para acceder a los inmuebles. La racionalidad mercantil al alcance de todos es una regla de coordinación de mercado que ofrece la armonía espacial en estos ambientes, en tanto, la proximidad del espacio físico, permite que la proximidad social produzca capital social, aprovechando los encuentros casuales y previsibles que garantizan que grupos heterogéneos de población frecuenten los lugares (Alfonso, 2005, p.188).

\section{Metodología}

Para analizar el anclaje de la renovación urbana en el Centro Histórico de la ciudad de Toluca a través del conjunto Paseo Molino, el alcance de la investigación está definido por un diseño no experimental transeccional exploratorio (Hernández, Fernández y Baptista, 2014), el enfoque analítico-empírico articula la reflexión teórica y contacto con los hechos.

Pensar en la verticalidad y horizontalidad de las edificaciones adquiere relevancia, porque es sobre esas cualidades en donde se aprecia el contraste entre lo moderno y lo no moderno, cuestión que remite al centro urbano fundador en el que se inserta el conjunto Paseo Molino. Por tratarse de un hecho inédito, el término anclaje de la renovación urbana alude al posicionamiento físico de una nueva forma de producir suelo urbano en el centro de una ciudad, dada su condición inicial se desconocen los efectos que ocasionará, con base en ello, surge la pregunta exploratoria siguiente: ¿Qué implicaciones tendrá el Paseo Molino en un sector urbano que desconoce de antecedentes semejantes?

La resolución de la interrogante partió del análisis de fuentes bibliográficas que abordan los procesos de renovación urbana en América Latina, información oficial que comprende estadísticas, cartografía, planes de desarrollo e informes de gobierno de seis administraciones locales, para sustentar la postura teórica, caracterizar el entorno urbano, la gestión y las condiciones del proyecto. Se aplicaron aleatoriamente 105 entrevistas semi estructuradas, dirigidas a personas que viven, visitan y/o trabajan en el centro histórico de la ciudad de Toluca, el objetivo fue recabar la opinión que los entrevistados tienen sobre los cambios de la imagen urbana en las dos últimas décadas. Los recorridos exploratorios se realizaron en un radio de dos kilómetros, con el objeto de registrar los cambios de uso de edificaciones históricas y complementar las perspectivas deductiva e inductiva para plantear la prospectiva de los impactos esperados y las conclusiones.

La validez teórica, metodológica y empírica a través de los resultados, la prospectiva y las conclusiones, documentan la excepcionalidad del caso, ofrece supuestos generales que anticipan y serán susceptibles de indagar y medir, por el momento es temprano para determinar su magnitud.

\section{Contexto del anclaje urbano}

La ciudad de Toluca de Lerdo es el núcleo urbano, administrativo, comercial y de servicios más importante de la quinta zona metropolitana del país (Zona Metropolitana de la Ciudad de Toluca). Se localiza en la porción central del Estado de México, a $72 \mathrm{~km}$ de distancia de la capital del país, cuenta con una superficie de 456,17 $\mathrm{km}^{2}$, que representa $2,04 \%$ del territorio estatal (COESPO, 2010).

Toluca de Lerdo cuenta con 873.536 habitantes, que representan $5,45 \%$ de la población estatal, la estructura por género expresa que $52 \%$ son mujeres (455.009 mujeres) y $48 \%$ hombres (418.527). Las viviendas habitadas ascienden a 218.639, con cuatro ocupantes promedio, $90,5 \%$ son casas, 3,43\% departamentos en edificios, 0,64\% vecindades o cuartería (INEGI, 2015). EI crecimiento demográfico identifica ciclos de ascenso y descenso; en el período 1980-1990, la población se 
incrementó 16 veces. En décadas siguientes, la tasa de crecimiento se redujo de $2,9 \%$ a $1,1 \%$ anual, la población urbana representa $58 \%$ de la total municipal.

En la ciudad de Toluca perduran las iglesias, monumentos, edificios administrativos, antiguas casonas y los portales testigos del patrimonio histórico. En el centro los testimonios identifican la plaza central, calles rectas de la traza ortogonal original, catorce barrios antiguos, como Santa Clara, la Merced (Alameda), San Sebastián, San Bernardino, La Retama, San Miguel Apinahuizco, la Teresona, Zopilocalco, el Cóporo, Santa Bárbara, Huitzila, San Luis Obispo, Tlacopa, San Juan Bautista (Orozco y Tapia, 2011). El centro fundador de la ciudad de Toluca conserva una mezcla de estilos arquitectónicos, inmuebles de los siglos XVIII y XIX (151 monumentos históricos 8 conjuntos arquitectónicos y 8 inmuebles con valor cultural ${ }^{1}$ ), edificaciones de poca altura, edificios públicos y actividades comerciales familiares, en las últimas tres décadas y como casos excepcionales repartidos aleatoriamente, surgen condominios con doce pisos de altura.

La meta de modernizar la ciudad a través de variados proyectos de mejora del paisaje y el ambiente urbano recupera iniciativas que obedecieron a ideas transformadoras que harían de lo antiguo una plataforma para captar capital a través del consumo cultural. Para ello se requería de normas para preservar los edificios antiguos y la declaratoria del Centro Histórico, la cual se logró hasta el año 2012. En este marco, cobró relevancia la revitalización estratégica del Centro Histórico, mediante la programación de acciones específicas: eco zona en el primer cuadro, huizi y ciclo vía primera etapa, remodelación del teatro de la ciudad y el andador González Arratia, cierre de calles, proyectos integrales del sector Alameda y parque estatal Matlatzincas (GEMPDUT, 2003, p.107). No obstante que la mayoría de los proyectos referidos se han realizado, el declive del centro histórico resume el decaimiento del comercio tradicional, congestionamiento vial y abatimiento del consumo, la solución pública orienta la revitalización de la economía del corazón de la ciudad y la revalorización del suelo urbano (Sánchez y Orozco Hernández, 2013).

Esta tendencia es un remake de la versión territorializada, que a mediados de los años noventa se planteó en la conferencia HABITAT II en Estambul, Turquía, en relación con la intervención del sector privado en la modernización de las ciudades (Schteingart, 2007, p.719). La conjunción de los intereses públicos y privados, remite a las nuevas formas de promoción urbana, el número de conjuntos urbanos autorizados en el municipio de Toluca, indica que prevalecen los destinados a vivienda de interés social. Hasta el año 2008 emergieron los conjuntos en las modalidades habitacional, residencial, comercial y de servicios; mixto (habitacional medio, comercio y servicios), medio y residencial, las inmobiliarias gestionan los proyectos (GEM, 2017). El conjunto urbano se estable como unidad espacial integral, localizable en predios urbanos o urbanizables, tiene por objeto estructurar y reordenar, el trazo de la infraestructura vial, la división del suelo, las normas de usos, aprovechamientos y destinos del suelo, las obras de infraestructura, el equipamiento urbano, la ubicación de edificios y la imagen urbana. El condominio vertical es una modalidad en la que cada condómino es propietario de un piso, departamento, vivienda o local, es copropietario de instalaciones de uso general (GEM, 2001, p.93).

\section{Retrospectiva del proyecto Paseo Molino}

El predio del proyecto corresponde a la antigua Harinera de Toluca, este inmueble se localiza en la manzana 39, de la Av. Sebastián Lerdo de Tejada No. 305 poniente, Centro Histórico, La Merced (Alameda), Toluca. No obstante que la antigua harinera está registrada en el catálogo de Monumentos Históricos e Inmuebles del Instituto Nacional de Antropología e Historia, con la clave I-1500482, y estaría sujeta a la política de preservación y conservación, dada la condición de propiedad privada del inmueble, los propietarios tienen derechos sobre el uso y destino de este bien. Luego de ser la Harinera de Toluca una de las industrias representativas de la ciudad, a lo largo de treinta años se abandonó el inmueble en espera de la oferta económica más atractiva, la edificación se

${ }^{1}$ Consulta pública del Catálogo de Monumentos Históricos INAH, México. Toluca 
deterioró debido a las inclemencias del tiempo (lluvia y temperatura). En 2014 parte de la fachada se colapsó por reblandecimiento a causa de la lluvia (Figura 1).

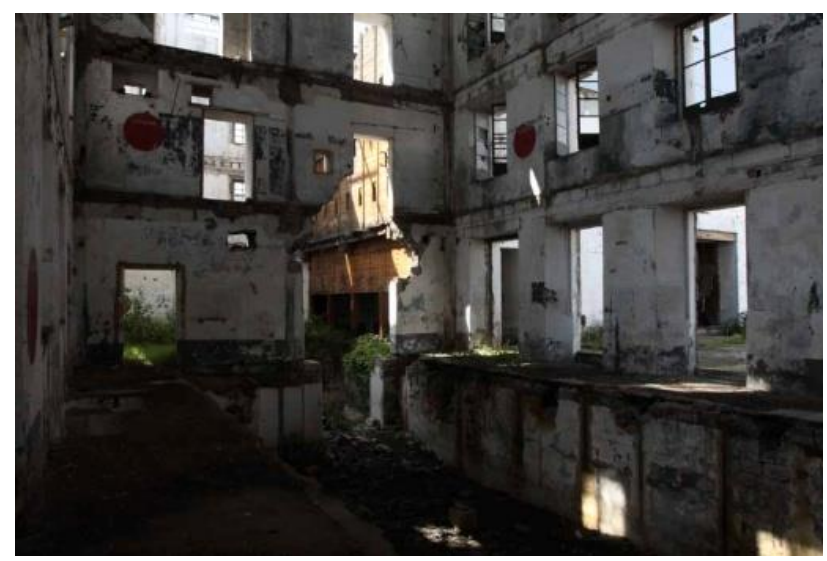

Figura 1. Estado de la antigua Harinera, 2014. Fuente: Redacción, 2018.

En el año 2010 se anunció la construcción del conjunto urbano Paseo Molino, la iniciativa se detuvo por carencia de recursos económicos, hasta el año 2014 se protocolizó la adquisición del inmueble, mediante la escritura que acredita la propiedad y el contrato de compraventa con reserva de dominio, celebrado por Moll Impulsora de Toluca S.A. de C.V. Banco Actinver, S.A. Institución de Banca Múltiple y Grupo Financiero Actinver. Una vez adquirido el inmueble figura la sociedad Plaza el Molino
S.A.P.I. de C.V., constituida el 04 de noviembre del dos mil trece, notariada en el Distrito Federal e inscrita en el Registro Público de la Propiedad y del Comercio bajo folio Mercantil.

\section{Autorización del proyecto Paseo Molino}

El libro Quinto del Ordenamiento Territorial de los Asentamientos Humanos y Desarrollo Urbano de los Centros de Población del Código Administrativo del Estado de México (GEM, 2001), establece las bases para planear, ordenar, regular, controlar, vigilar y fomentar el ordenamiento territorial de los asentamientos humanos y el desarrollo urbano de los centros de población. Los conjuntos urbanos deben cumplir con los lineamientos dispuestos en los Planes Municipales de Desarrollo Urbano, la Secretaría de Desarrollo Urbano y Metropolitano establece las normas técnicas para autorizar los proyectos, supervisa las obras, infraestructura y equipamiento de los conjuntos urbanos y las subdivisiones de más de $6.000 \mathrm{~m}^{2}$ (GEM, 2001, p.93). La autorización integra licencias y dictámenes emitidos por dependencias y organismos auxiliares de la administración pública federal, estatal y municipal. EI procedimiento consta de veinte trámites y variados requisitos para que se lleven a cabo los proyectos (Figura 2). 


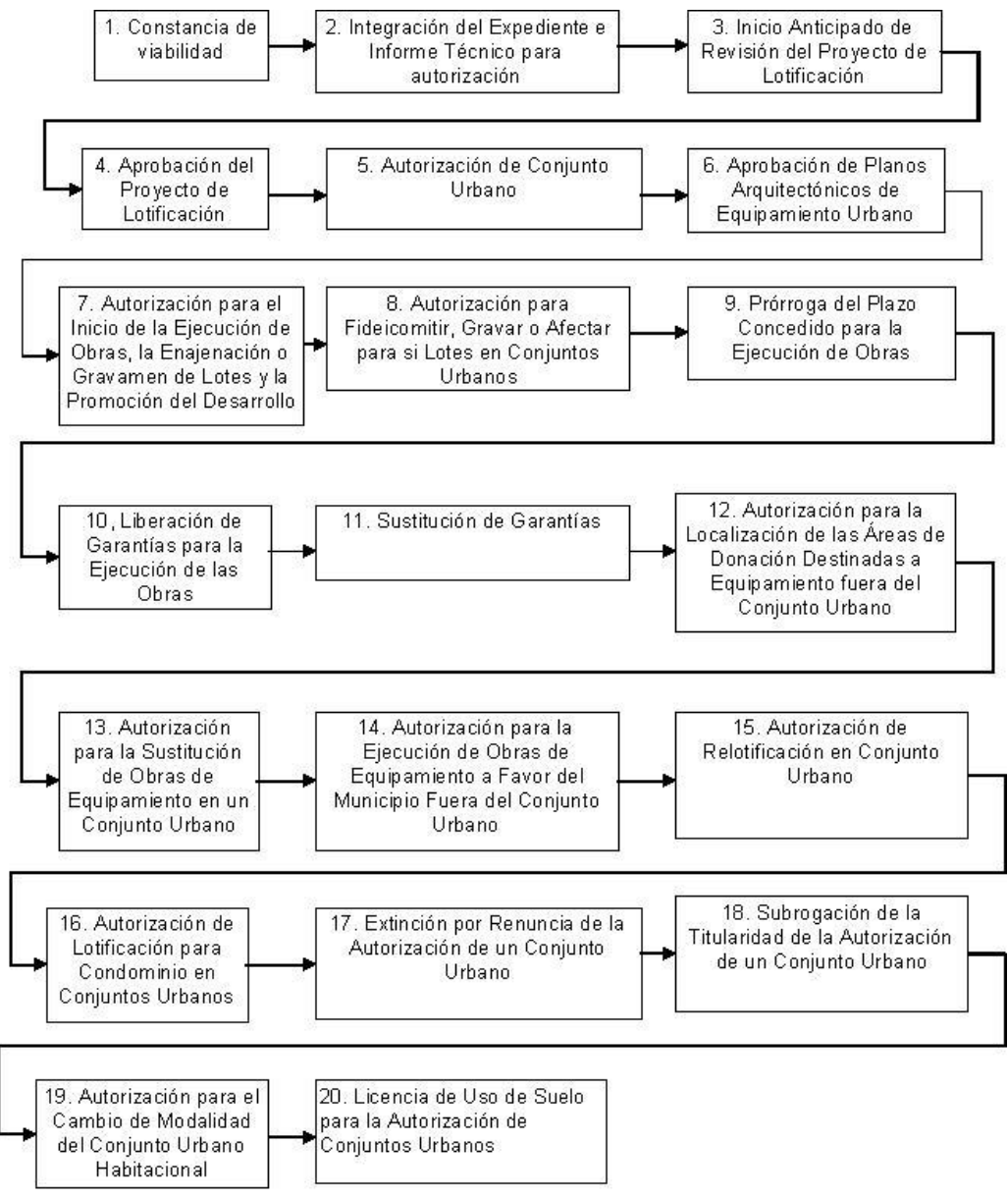

Figura 2. Etapas para autorización de conjuntos urbanos, Estado de México. Fuente: Elaboración propia, con base: GEM,2017.

Las instancias involucradas en la aprobación, identifica al gobierno del Estado de México a través de instancias de primero y segundo nivel. Por ejemplo, la Secretaría de Desarrollo Urbano y Metropolitano y la Secretaría del Medio Ambiente: Dirección General de Protección Civil, Dirección General de Ordenamiento e Impacto Ambiental, Dirección General de Vialidad, Comisión del Agua del Estado de México. También el Departamento de Planeación y Construcción Zona Toluca; Dirección General de Planeación Urbana, Dirección General de Vialidad, Dirección General de Ordenamiento e Impacto Ambiental, y la Comisión Federal de Electricidad.

La participación del Ayuntamiento de Toluca se acota a la manifestación de acuerdo sobre el proyecto (18-07-
2014), acreditación de la emisión del dictamen de factibilidad de los servicios de agua potable y drenaje (0307-2014), emisión de la constancia de alineamiento y número oficial, y señalización de restricciones absolutas de construcción (03-12-2015). El proceso se resolvió en tres años.

El 12 de abril de 2016 se solicitó a la Dirección Regional Valle de Toluca, adscrita a la Dirección General de Operación Urbana dependiente de la Secretaria de Desarrollo Urbano y Metropolitano, la autorización para llevar a cabo la subdivisión en dos lotes y dos condominios verticales mixtos de tipo habitacional, comercial, servicios y oficinas para desarrollar el conjunto urbano El Molino en una superficie de $7.562 \mathrm{~m}^{2}$ (Figura 3). 


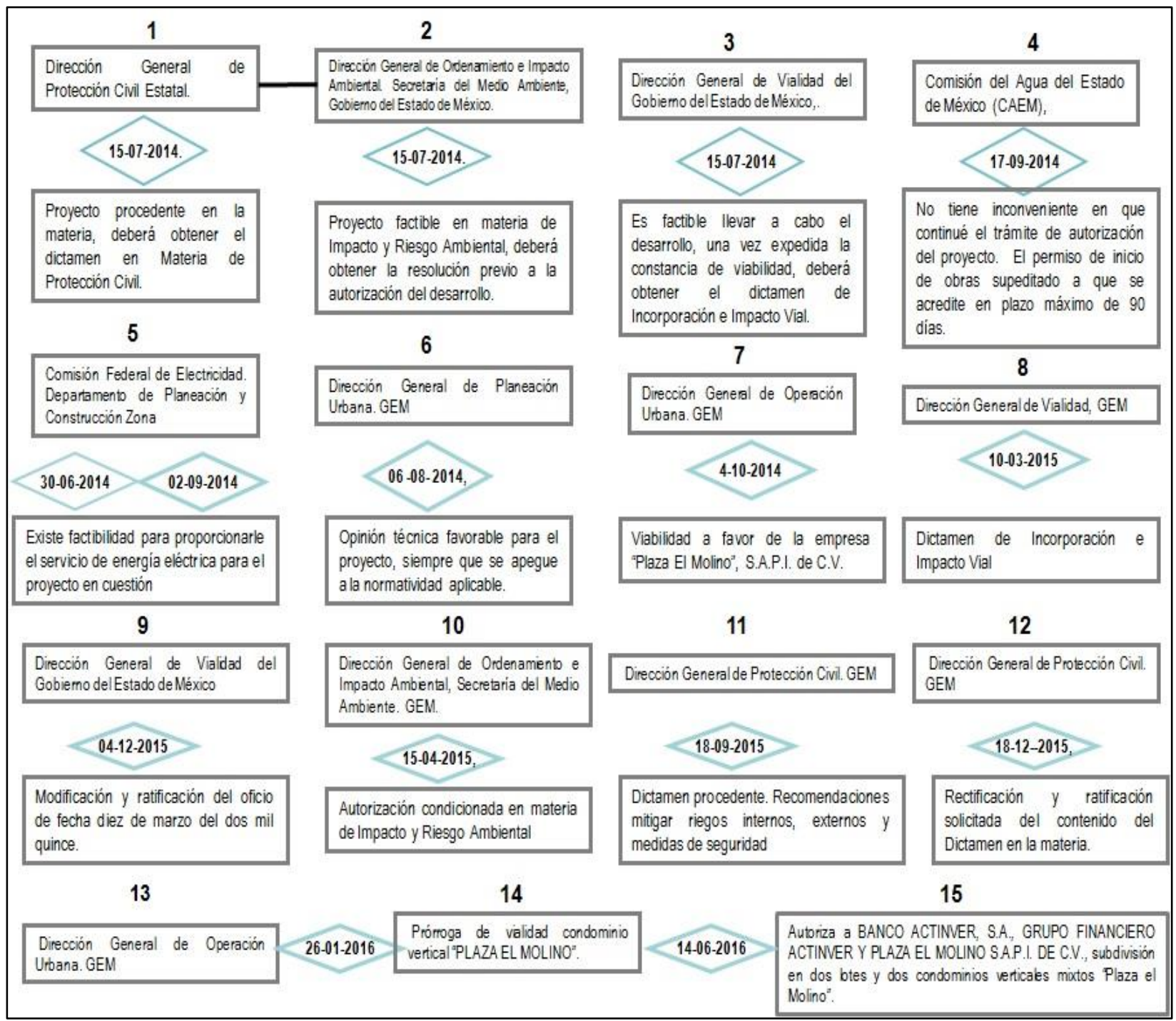

Figura 3. Proceso de aprobación del proyecto El Molino, 2014-2016. Fuente: Elaboración con base en: GEM (2016).

La Dirección General de Operación Urbana del municipio de Toluca, emitió el acuerdo por el que se autoriza Plaza el Molino S.A.P.I. de C.V., cambio de densidad, coeficiente de ocupación e Incremento de altura del inmueble. Tratándose de un proyecto impulsado por el gobierno estatal, las áreas de donación destinadas a equipamiento urbano se expidieron a favor del municipio de Metepec y no a favor del municipio de Toluca. La Secretaría de Desarrollo Urbano y Metropolitano publicó el acuerdo por el que se autoriza a la empresa Banco Actinver, S.A. Institución de banca múltiple, Grupo Financiero Actinver (fiduciario) y Plaza el Molino S.A.P.I. de C.V., la subdivisión en dos lotes y dos condominios verticales mixtos de tipo habitacional, comercial, servicios y oficinas para desarrollar 156 viviendas de tipo medio y un área de construcción para comercio, servicios (8) y oficinas (5); con una superficie total de $7.562 \mathrm{~m}^{2}$. Denominado Paseo Molino.

\section{Entorno urbano de Paseo Molino.}

El conjunto vertical Paseo Molino se localiza el Barrio la Merced (Alameda) en el primer cuadro del centro histórico de la ciudad de Toluca. El entorno urbano y social se conforma por 1.691 habitantes, $44 \%$ hombres y $56 \%$ mujeres, de los cuales el $70 \%$ es originaria del Estado de México y $30 \%$ inmigraron de otra entidad. Los sectores de población dominantes cuentan con una edad entre 25 y 49 años, y 60 años y más. 
La proporción de la población étnica es de $12 \%$, poco más del $80 \%$ de los residentes profesan la religión católica; el sector de población de 12 años y más (1.364), identifica los solteros con $43 \%$, casados $40 \%$, separados $17 \%$. La mayor parte de la población está en edad de trabajar, la escolaridad promedio es 12.8 años (primaria, medio superior y superior). Presenta una densidad de población inferior a la media estatal (724 hab/km2) y un patrón de ocupación compacto. El equipamiento cercano identifica los siguientes hitos espaciales: el parque municipal Cuauhtémoc o Alameda, la Plaza González Arratia, el Teatro de la ciudad, la catedral, andadores y calles (Figura 4).

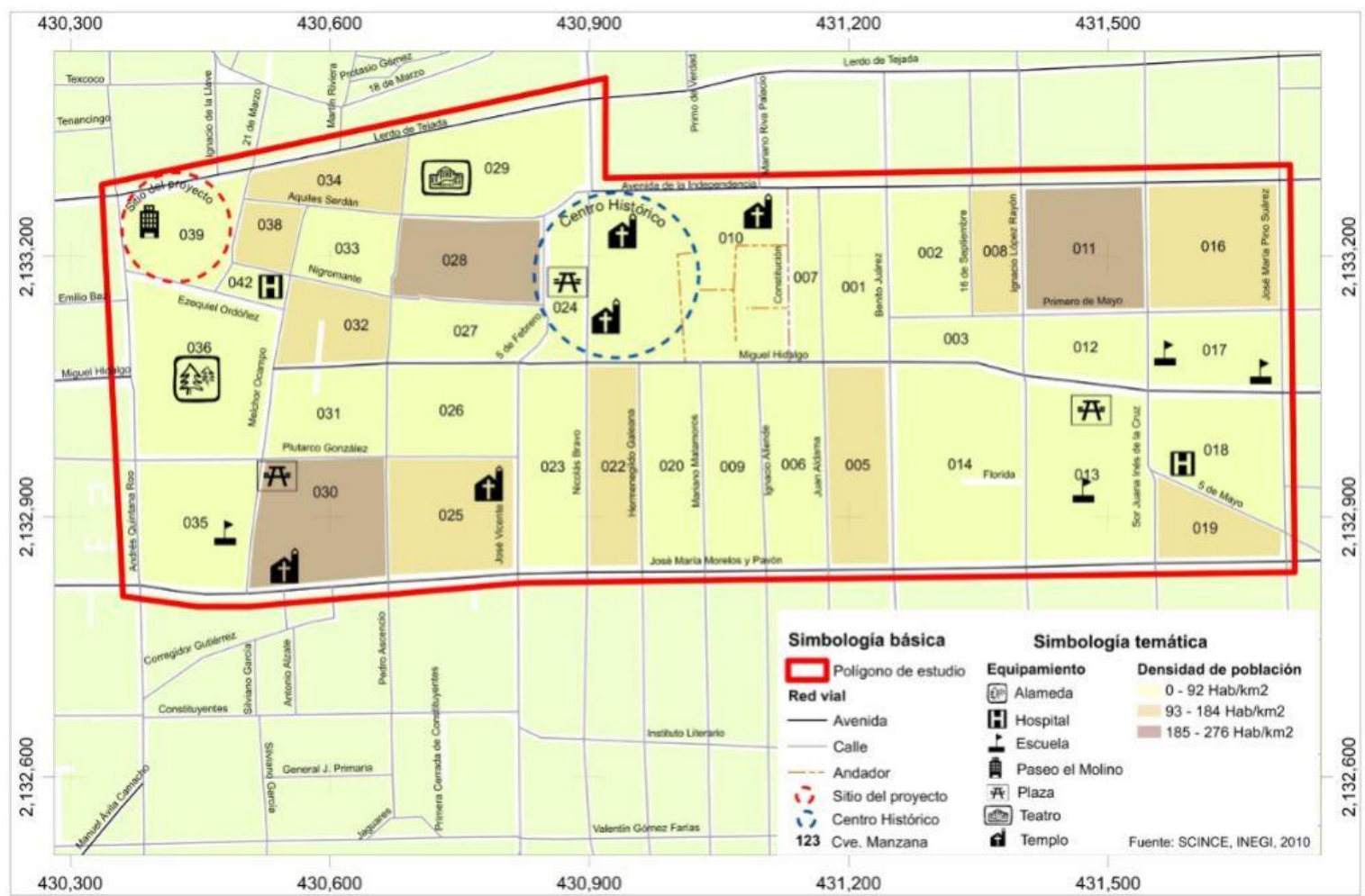

Figura 4. Entorno urbano del proyecto Paseo Molino. Fuente: elaboración con base a INEGI (2010).

El área da cabida a 525 hogares; $58 \%$ con jefatura masculina y $42 \%$ femenina, y 790 viviendas, de las cuales el $70 \%$ alberga en promedio 3 ocupantes. El $94 \%$ de las viviendas habitadas dispone de servicios básicos: electricidad, agua potable, excusado, drenaje y bienes que indirectamente dan cuenta de las condiciones de vida de los habitantes: radio (86\%), televisión (92\%), refrigerador (89\%), lavadora (71\%), automóvil (50\%), computadora $(60 \%)$, teléfono $(60 \%)$, celular $(82 \%)$, internet $(47 \%)$. La población ocupada representa $49 \%$ de la población es económicamente activa (PEA) y el índice de desempleo es 3,1\% (INEGI, 2016).
Resalta el uso de suelo habitacional-comercial (mixto), el uso propiamente habitacional no es representativo. Los propietarios de casas habitación en la primera planta desarrollan comercio de abasto al por menor: panaderías, tiendas de abarrotes, minisúper, fruterías-verdulerías, farmacias, papelerías, gasolinera, lavanderías, consultorio dental, entre otros.

El área cuenta con recubrimiento de calles, banquetas, guarnición, disponibilidad de alumbrado público y teléfono público en algunas vialidades. No tiene restricciones para peatones y automóviles. En la manzana del proyecto y en la Alameda o parque central de la ciudad, algunas vialidades presentan puestos semifijos, en tanto que los puestos ambulantes se ubican en manzanas 
contiguas. También se localizan centros educativos de varios niveles: bachillerato; preescolar; primaria $y$ secundaria. Los servicios, las funciones comerciales y el equipamiento urbano, conforman un entorno atractivo para los residentes, visitantes locales y foráneos. La cobertura de la infraestructura, equipamiento urbano y de servicios en la vivienda, es superior a 90\%, lo que indica rezago social muy bajo (CONEVAL, 2010) (Figura 5).

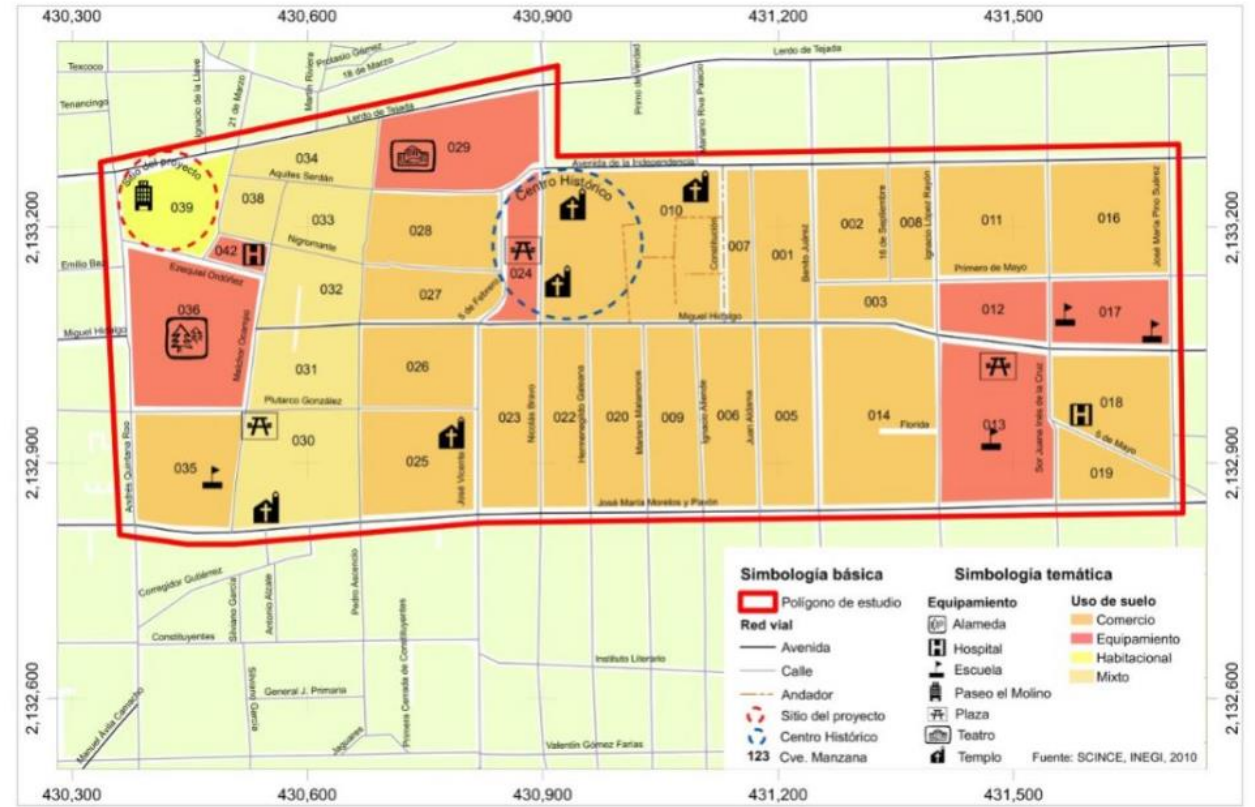

Figura 5. Usos del suelo en el entorno urbano de Paseo Molino. Fuente: elaboración propia con base a INEGI (2010).

Estado del conjunto urbano mixto: Paseo Molino. EI conjunto urbano consta de áreas designadas al uso comercial, oficinas y departamentos tipo loft, la base se conforma de cuatro sótanos por cada torre, los tres primeros niveles están destinados al uso comercial y de servicios. El uso habitacional se dispone en el condominio 1 a partir del nivel 3 al 10 y en el condominio 2 a partir del nivel 3 al 11, para aprovechar la vista de la ciudad (igura 6).

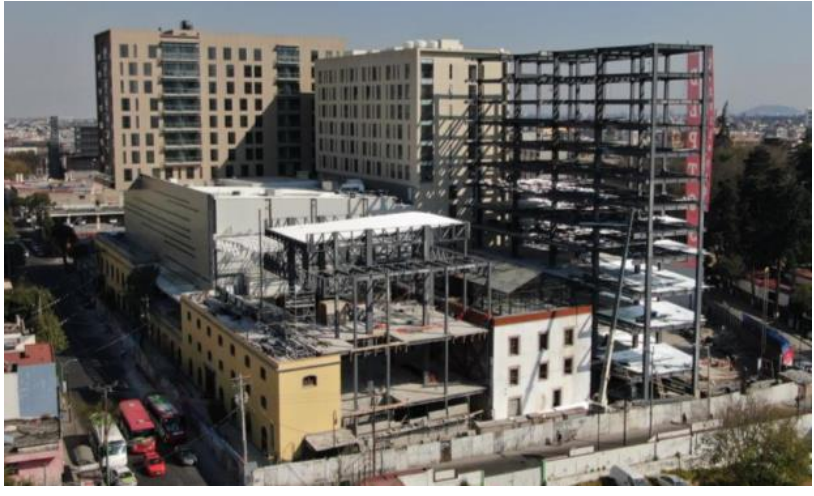

Figura 6. Paseo Molino vista actual. Fuente: Revista Centro Urbano.

El costo máximo varía de acuerdo con la superficie, los servicios, la vista y el nivel de ubicación de cada departamento. Cuenta con terraza en una superficie de $302 \mathrm{~m}^{2}$ (Tabla 2). 
Tabla 2

Costos y servicios Paseo el Molino

\begin{tabular}{|c|c|c|c|c|c|c|c|c|}
\hline $\begin{array}{c}\text { Prototipo } \\
\text { departament } \\
0\end{array}$ & $\begin{array}{l}\text { Superficie de } \\
\text { construcción }\end{array}$ & Habitación & $\begin{array}{l}\text { Servicios } \\
\text { Baños }\end{array}$ & $\begin{array}{l}\text { Cajones } \\
\text { estaciona } \\
\text { miento }\end{array}$ & Precio $^{2}$ & $\begin{array}{l}\text { Pago } \\
\text { inicial }\end{array}$ & $\begin{array}{c}\text { Monto } \\
\text { préstamo }\end{array}$ & $\begin{array}{c}\text { Pago } \\
\text { mensual }\end{array}$ \\
\hline O-P & $72 m^{2}-74.85 m^{2}$ & 2 & 2 & 1 & $\$ 2.490 .000-\$ 2.600 .375$ & $\$ 249.000$ & $\$ 2.241 .000$ & $\$ 20.163$ \\
\hline $\mathbf{Q}$ & $135 \mathrm{~m}^{2}$ & 2 & 2,5 & 2 & $\$ 4.279 .600-\$ 4.674 .750$ & $\$ 427.960$ & $\$ 3.851 .640$ & $\$ 34.654$ \\
\hline $\mathbf{R}$ & $149 m^{2}-248 m^{2}$ & 2 & 2,5 & 2 & $\$ 5.420 .500-\$ 6.755 .100$ & $\$ 541.050$ & $\$ 4.484 .450$ & $\$ 43.893$ \\
\hline $\mathbf{M}$ & $162 \mathrm{~m} 2$ & 3 & 3,5 & 2 & $\$ 5.200 .000-\$ 5.605 .560$ & $\$ 520.000$ & $\$ 4.680 .000$ & $\$ 42.107$ \\
\hline $\mathbf{N}$ & $150 m^{2}-260 m^{2}$ & 3 & 2,5 & 2 & $\$ 4.800 .000-\$ 7.281 .938$ & $\$ 480.000$ & $\$ 4.320 .000$ & $\$ 38.868$ \\
\hline Planta Baja & $4.509,83 \mathrm{~m}^{2}$ & & & & $\$ 425$ / m2. & & & \\
\hline Nivel 1 & $4.416,37 \mathrm{~m}^{2}$ & \multicolumn{3}{|c|}{ Comercio y servicios } & $\$ 375$ / m2. & \multirow{2}{*}{\multicolumn{3}{|c|}{$\begin{array}{l}\text { Mantenimiento: } 15 \% \text { de la renta } \\
\text { mensual. }\end{array}$}} \\
\hline Nivel 2 & $3.686,96 \mathrm{~m}^{2}$ & & & & $\$ 200 /$ m2. & & & \\
\hline
\end{tabular}

Elaboración propia con base a la Gaceta de Gobierno. Núm. 001102, junio 2016.

La expectativa comercial de uso habitacional se dirige al sector de población joven, las cualidades las determina la solvencia económica, la capacidad crediticia e ingreso mayor a diez salarios mínimos. El rendimiento económico potencializa el uso comercial del inmueble. Área gastronómica, centro de entrenamiento con tecnología de punta, dos estacionamientos y $10.000 \mathrm{~m}^{2}$ de área de esparcimiento. Diversas firmas atenderán a residentes y visitantes bajo las siguientes marcas: BBVA Bancomer, Starbucks, Café Madero, Local Toyo Deslumbra, Santa Clara, Smart Fit y Cinepolis, Subway, Maxi donas y otros más. Las ventajas identifican la dotación de infraestructura, cuya funcionalidad futura no precisa gastos adicionales en acondicionamiento $o$ medidas extraordinarias en ordenación y urbanización. La rentabilidad de la oferta habitacional y comercial garantiza el rendimiento de la inversión que asciende a 520 millones de pesos mexicanos.

\section{Discusión de resultados}

No obstante que la política del gobierno local dispone atraer flujos de inversión privada, mediante la desregulación y proyectos autofinanciables ( $\mathrm{H}$. Ayuntamiento de Toluca, 2016, p.38). Los obstáculos se encuentran en el nivel de profesionalización de los servidores públicos y las distorsiones fiscales, los gobiernos no están preparados para el manejo gerencial de la competitividad urbana (Cabrero, 2009). Los gobiernos estatal y local se han alineado a las tendencias de la gestión descentralizada que deja a manos libres al sector privado para la construcción, financiación y comercialización de bienes inmuebles de gran formato, centros comerciales, conjuntos habitacionales de interés social, medio y alto estándar diseminados sin un patrón definido.

Las políticas centran la gestión bajo la lógica de la segmentación y especialización urbana, esta tendencia ha dado personalidad propia al urbanismo inmobiliario y lo ha posesionado como pieza clave del circuito de acumulación neocapitalista. El sector inmobiliario urbano, componente central del circuito secundario del capital, es el moderador de la caída general de la tasa de ganancia y, el espacio económico predilecto para la emergencia de nuevos capitales (Alfonso, 2005, p.169).

Las inversiones en activos fijos producen espacio urbano y la triada de agentes implicados reúne los intereses de los inversionistas de la construcción, el sector financiero y las políticas públicas que ofrecerían soporte

${ }^{2}$ Los precios en pesos mexicanos 
de largo plazo (Harvey, 1973). En la producción de emprendimiento Paseo Molino, intervinieron diversos actores: históricos, políticos y privados que inauguraron el conjunto vertical como forma novedosa y rentable para crear espacio urbano.

El modelo de intensificación de uso del suelo urbano se gestionó a través de mecanismos administrativos, mercantiles, civiles y financieros. Los actores identifican el icónico objeto de la transformación (Molino de Harina La Unión), los actores públicos, el Instituto Nacional de Antropología e Historia, los gobiernos estatal y municipal, la política de apertura y desregulación.
Los privados, el régimen privado de la propiedad y su trasmisión a través de un contrato de compraventa con reserva de dominio, celebrado por Moll Impulsora de Toluca S.A. de C.V. (fideicomitente); Banco Actinver, S.A. Institución de Banca Múltiple y Grupo Financiero Actinver (financiadores) y la sociedad Paseo Molino S.A.P.I. de C.V. (fiduciaria) encargada de conservar la propiedad de los bienes y transmitir los beneficios a favor de terceros (fideicomisario). Esta forma de operar instituye el fideicomiso como mecanismo que abate riegos, garantiza la inversión y la rentabilidad de las modernas intervenciones urbanas (Figura 7).

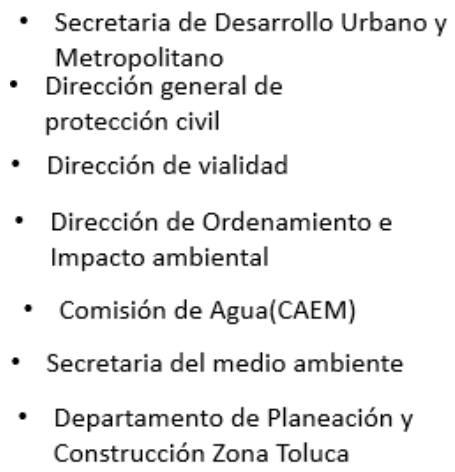

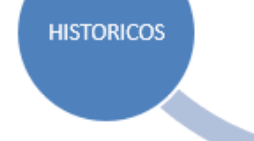

Dirección General de Operación Urbana

Municipal

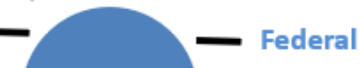

- Comisión Federal de Electricidad (CFE)

- Instituto Nacional de Antropología e Historia (INAH)

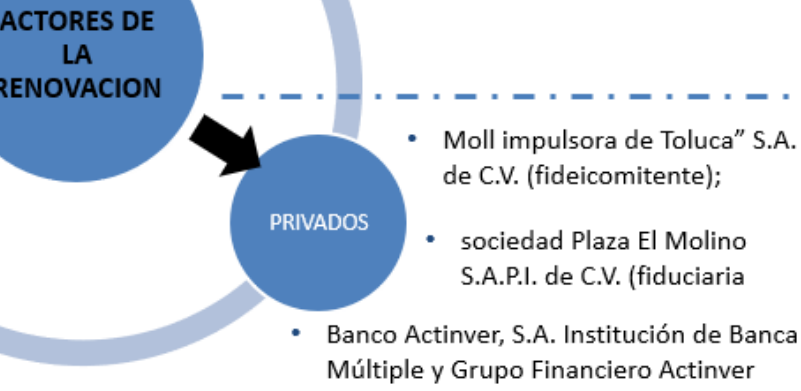

- Moll impulsora de Toluca" S.A. de C.V. (fideicomitente);

- sociedad Plaza El Molino S.A.P.I. de C.V. (fiduciaria

- Banco Actinver, S.A. Institución de Banca Múltiple y Grupo Financiero Actinver (financiadores)

Figura 7. Agentes de la Renovación en caso Paseo el Molino. Fuente: elaboración propia.

La edificación en altura de Paseo Molino se sirvió de las ventajas comparativas del suelo urbanizado, la localización y el valor de situación del centro histórico de la ciudad de Toluca. La localización incide en la formación de los precios del suelo urbano, pero la intensidad de capital aplicada al suelo - número de edificios construidos en un mismo lote- y las actividades residenciales y comerciales, multiplican las ganancias excepcionales y en términos cuantitativos incidirán en el incremento de los precios del suelo a futuro (Jaramillo, 2003). La competencia coordinada por el mercado, obtiene una distribución espacial de los diferentes tipos de familia, del consumo de espacio (densidad) y la intensidad de construcción (verticalidad) que maximiza la rentabilidad del uso del espacio urbano de elección individual (Alfonso, 2005).

\section{Prospectiva}

El anclaje de la renovación urbana a través del conjunto Paseo el Molino en el centro histórico de la ciudad de Toluca es un hecho inédito que alude al posicionamiento físico de una nueva forma de producir suelo urbano, dada su condición inicial se desconocen los efectos que ocasionará, sin embargo, el análisis de la situación actual, anticipa algunos aspectos por venir. 
El Paseo el Molino identifica un caso atípico en el contexto del centro histórico de la ciudad de Toluca, abarca especificaciones de ingeniería para la construcción, oferta de vivienda, espacios comerciales y oficinas en un conjunto. Las implicaciones que tendrá su anclaje en un sector de la ciudad que no conoce de antecedentes semejantes, lleva a las aportaciones de Robert E. Park (Bettin, 1982), cuando en la tercera década del siglo XX se refería a la ciudad de Chicago en pleno proceso de cambio social y espacial, teorizó sobre un proceso triple denominado competencia, predominio y sucesión entre las actividades y usos de suelo en un contexto urbano marcado por las transformaciones modernizadoras.

Si se aborda la competencia se estaría hablando de recursos limitados sobre los cuales se ejerce presión, particularmente el agua potable que se requerirá para abastecer a los espacios comerciales y a las viviendas en condominio. La presión que se ejerza sobre el agua podría conllevar a tensiones entre los habitantes de las áreas de vivienda popular horizontal que bordean al conjunto vertical y se asientan en las calles de Andrés Quintana Roo, Sebastián Lerdo de Tejada y 21 de marzo, y la policlínica en la calle Ezequiel Ordoñez.

Otro recurso es el espacio para la circulación vehicular, que con o sin la presencia del conjunto urbano manifiesta problemas en las vialidades, en particular en las calles de Quintana Roo, Ezequiel Ordoñez y 21 de marzo, estas son vialidades con $6 \mathrm{~m}$ de ancho por donde solamente se permite la circulación simultánea de dos vehículos, debido a que un tercer carril ha sido transformado en ciclo vía. En horas de punta los problemas de circulación se agravan y en especial por la presencia del hospital en la calle 21 de marzo. Habría que agregar que el proyecto del Molino está diseñado para personas que usan automóvil como forma predominante de movilidad.

Queda abierta la interrogante si la competencia comercial que traerá el proyecto Paseo Molino romperá la oferta comercial local o la desplazará, porque este proyecto trae nueva oferta en cuanto a formatos de comercialización a partir de tiendas departamentales, relativamente ajenas a una zona de pequeños comercios cuya desaparición no puede adelantarse, pero la proximidad física perfila la siguiente situación.

Tomando en cuenta que la oferta del comercio local podría no entrar en conflicto con la oferta de la plaza comercial Paseo Molino. En su lugar, podría darse un proceso de complementariedad de ofertas, en la actual y la futura, especialmente esta última podría derramar beneficios a la población que habita en las inmediaciones del lugar, cuya capacidad adquisitiva los coloca en una posición de clientela potencial para el Molino.

La interpretación de las consecuencias morfológicas, sociales y económicas identificadas en los estudios con énfasis en la rehabilitación, re-funcionalización, revitalización, recuperación urbana y renovación urbana. Advierten que las intervenciones en edificaciones con uso habitacional comprenden transformaciones de alta y baja intensidad. En orden de aparición se identifica la transformación de la imagen urbana, sustitución de usos y funciones, aumento de valor del suelo, especulación inmobiliaria, desplazamiento de residentes, exclusión de sectores de población de bajos ingresos por el costo de las nuevas edificaciones y transformación social.

En el país es conocido el desalojo por la fuerza de los residentes de las vecindades del centro histórico de la ciudad de México, identifica una débil y obsoleta Ley inquilinaria, carencia de seguridad jurídica y recursos económicos de las familias que rentan las edificaciones antiguas, también las invasiones de terrenos de propiedad social hasta los años noventa, cuya regularización posterior dio origen a las colonias populares y a la expansión de la ciudad. Una vez regularizada la propiedad, adquirieron mayor valor y se convirtieron en objeto de consumo.

Ambos ejemplos contextualizan procesos de desalojo (evacuación, desocupación); desplazamiento (distancia y cambió de lugar) y sustitución (reemplazar y desplazar) de población, los cuales establecen momentos distintos, el desalojo en el caso citado está mediado por la irregularidad de la propiedad y la violencia física, en otros casos por causas de fuerza mayor, como una contingencia que podría afectar la integridad de las personas.

Las motivaciones o motivos pueden ser variados, sin embargo, en la medida que un espacio urbano se habilita atraerá población distinta y producirá desplazamiento de los residentes a otro lugar. Por ello, es pertinente redimensionar el contexto específico e histórico en el que ocurre la transformación social. En el caso estudiado todavía es temprano para aventurar dicha transformación, la factibilidad de que el proyecto Paseo 
Molino revalorice las propiedades circunvecinas, enfrenta el fuerte arraigo de los residentes a su lugar de nacimiento y habitación, es probable que la población que en buena parte se encuentra en estado de madurez, no sucumba a las expectativas del mercado del suelo.

En cambio, al norte de la vialidad en la que se ubica Paseo Molino -Vialidad Lerdo de Tejada-, los asentamientos humanos identificados en el cerro localmente denominado La Teresona, las colonias de San Miguel Apinahuizco y Popular, la compra- venta de las propiedades y la sustitución de población son comunes, por lo que no es previsible si el conjunto acelerará o no estos procesos.

\section{Conclusiones}

El conjunto Paseo el Molino muestra que la renovación urbana mediante la intensificación del uso del suelo es un proceso en ciernes en el centro histórico de la ciudad de Toluca. Su excepcionalidad expresa que la intervención urbanística es una estrategia que se empleada como una herramienta del quehacer político e incremento de capitales

El gobierno local plantea metas multifinalitarias difíciles de equilibrar, entre ellas, recuperar el espacio público, mejorar la calidad de vida de los residentes, atraer visitantes e impulsar la movilidad sustentable a través de proyectos de remodelación y rehabilitación. Por otro lado, el gobierno estatal favorece la inserción de anclajes urbanos, los cuales emergen espontáneamente, sin ningún plan o política que haya previsto su existencia y los aglomere en un sector de la ciudad.

Ante la inminente pérdida de protagonismo de centralidad económica y espacio de socialización urbana del centro histórico de la ciudad Toluca. La actuación pública pretende resolver la crisis a través de la autorización de proyectos espontáneos y actividades comerciales y de servicios de nueva generación.

Los gobiernos y sector privado definen una correlación de fuerzas que trasciende el proceso de gestión, autorización y ejecución del proyecto planificado Paseo Molino.

La inserción del conjunto residencial y comercial Paseo Molino en un área que no es residencial, indica el alcance de metas satisfactoria y óptimas que definen las expectativas de los actores involucrados, para el gobierno local significará captación de impuestos, lo cual no compensará el gasto para mantener los servicios públicos. Por el lado de los intereses mercantiles, el acondicionamiento del predio con edificación nueva incidirá directamente en los costos y las ganancias que definen la rentabilidad urbana. El incremento futuro del valor del inmueble y de las áreas circunvecinas se deberá a las acciones públicas: cambios de densidad, equipamiento urbano, vialidades, entre otras, mejoras que serán cubiertas por las contribuciones de los ciudadanos.

La materialización del conjunto vertical Paseo Molino promovida por los intereses de los sectores inmobiliarios y financieros capitaliza el espacio aéreo y contrapone el derecho a la ciudad habitable para todos. Este segmento urbano, especialmente la sala de cine atrae población joven y adolescente de distinto estatus social, creando el imaginario de la proximidad social. Sin embargo, la exclusión de facto está determinada por el poder adquisitivo y los mecanismos mercantiles que establecen los criterios de acceso.

Los impactos futuros en la economía y en las estructuras social, son todavía inciertos. Sin embargo, la inmediatez acusa la ruptura de la morfología e imagen urbana precedente; las características de los destinatarios de los departamentos, asociados al precio, excluye de facto a la población que no cumple con los requisitos de crédito y financiación para acceder a la oferta habitacional. Los comercios y las amenidades del conjunto urbano rebasan la demanda de los residentes, aunque el principio mercantil plantea la expectativa de atraer a la clientela potencial.

Se anticipan conflictos por el servicio agua y el espacio público de las vialidades, así como en el sustento estructural de la economía local, el comercio familiar. Las transformaciones previsibles identifican la revalorización de las propiedades circunvecinas, así como la venta de propiedades en las colonias populares y la sustitución de población.

El anclaje urbano de la renovación urbana fija el germen de los cambios que impulsa el capital inmobiliario y las tendencias globalizantes en el corazón de la ciudad de Toluca.

Sin embargo, el conjunto Paseo Molino prevé bajo impacto multiplicador en el fortalecimiento de la 
competitividad urbana y la cohesión social, debido a la ausencia de objetivos e instrumentos de gestión que direccionen la urbanización de lo urbano.

El reacomodo de las relaciones entre el gobierno y el sector privado que intervienen en la renovación de las condiciones físicas e infraestructurales de fragmentos de la ciudad, enfrentará la continuidad de un pasado que se remonta a casi dos siglos, que en lo sucesivo constituirá un factor que podría frenar la multiplicación de las edificaciones verticales en el centro histórico de la ciudad de Toluca [B]

\section{Referencias}

Alfonso, O. (2005). La ciudad segmentada: una revisión de la síntesis espacial neoclásica. Revista de Economía Institucional, 7(13), 159-191. Recuperado de http://www.scielo.org.co/scielo.php?script=sci arttext\&pid =S0124-59962005000200007\&lng=en\&t|ng=.

Balbo, M., Jordán, R. y Simioni, D. (2003). La Ciudad Inclusiva. CEPAL: Santiago de Chile.

Bettin, G. (1982). Los Sociólogos de la Ciudad. Barcelona: Gustavo Gili.

Brunet, R. (1993). Les Mots de la Géographie. Dictionnaire critique. París: Editorial Reclus, Montpellier.

Cabrero M., E. (Coord.) (2009), Competitividad de las ciudades en México. La nueva agenda urbana, México, CIDE: Secretaría de Economía. México D.F.

Campesino, F. A. (1989). La rehabilitación integrada de los centros históricos: el reto urbanístico de finales de los ochenta. Investigaciones Geográficas, (7), 7-17. https://doi.org/10.14198/INGEO1989.07.02

Carrión, F. (2003). Ciudad y Centros Históricos, en la Ciudad Inclusiva. Santiago de Chile: CEPAL.

Carrión, F. (2010). El laberinto de las centralidades históricas en América Latina. Quito: Ministerio de Cultura.

COESPO (2010). Diagnóstico sociodemográfico del municipio de Toluca. Recuperado de: https://www.ipomex.org.mx/recursos/ipo/files ipo/2 013/33/7/7d024ff22cfc66eb398c17f9db6f35b9.pdf

Consejo Nacional de Evaluación de la Política de Desarrollo Social [CONEVAL] (2010). Datos sobre la carencia por calidad y espacios de la vivienda. Recuperado de: http://www.coneval.org.mx/paginas/principal.aspx

Contreras, Y. (2011). La recuperación urbana y residencial del centro de Santiago: Nuevos habitantes, cambios socioespaciales significativos. Revista EURE, XXXVII (112), 89-113. http://dx.doi.org/10.4067/S0250$\underline{71612011000300005}$
De Mattos, C., Riffo, L., Yáñez, G. y Salas, X. (2004). Reestructuración del mercado metropolitano de trabajo y cambios socio territoriales en el Gran Santiago. Santiago: Instituto de Estudios Urbanos y Territoriales - INE. PUC.

Falú, A. y Marengo, C. (2004). Las políticas urbanas: desafíos y contradicciones. En Ana Clara Torres Ribeiro (Comp.), El rostro urbano de América Latina, pp.211-228. Buenos Aires: Consejo Latinoamericano de Ciencias Sociales.

Gobierno del Estado Libre y Soberano de México (2001). Libro Quinto del Ordenamiento Territorial de los Asentamientos Humanos y del Desarrollo Urbano de los Centros de Población del Código Administrativo del Estado de México vigente. Recuperado de https://legislacion.edomex.gob.mx/sites/legislacion.e domex.gob.mx/files/files/pdf/rgl/vig/rglvig107.pdf

Gobierno del Estado Libre y Soberano de México. (Martes 14 de junio de 2016). Periódico Oficial. Gaceta. Sección Primera. Tomo CCl, Número 108. Toluca de Lerdo, México. Recuperado de https://legislacion.edomex.gob.mx/sites/legislacion.e domex.gob.mx/files/files/pdf/gct/2016/jun141.pdf

Gobierno del Estado de México (2001). Código Administrativo del Estado de México. Recuperado de http://legislacion.edomex.gob.mx/codigos/vigentes,

Gobierno del Estado de México (2003). Plan Municipal de Desarrollo Urbano de Toluca, Toluca México. Recuperado de http://seduv.edomexico.gob.mx/planes municipales/ Toluca/PMDU-tol.pdf

Gobierno del Estado de México (2017). Conjuntos Urbanos. Recuperado de: https://seduym.edomex.gob.mx/conjuntos urbanos

Gobierno del Estado de México (2017). Secretaría de Desarrollo Urbano y Metropolitano Autorización de Conjuntos Urbanos, 1999-2017. Recuperado de http://sedur.edomex.gob.mx/autorizaciones 
Gioria, B. (2003). Refuncionalización de terrenos del puerto y ferrocarril en la ciudad de Santa Fe. Biblio 3 W Revista Bibliográfica de Geografía y Ciencias Sociales, 8(448). Recuperado de http://www.ub.edu/geocrit/b3w-448.htm

Goulart, R. (2005). La rehabilitación y la renovación urbana en la ciudad de Río de Janeiro y sus perspectivas. Scripta Nova, Revista electrónica de Geografía y Ciencias Sociales, 9(194). Recuperado de http://www.ub.edu/geocrit/sn/sn-194-44.htm

H. Ayuntamiento de Toluca (2016). Bando Municipal 2016-2018. Recuperado de http://www.toluca.gob.mx/bando-municipal/

Harvey, D. (1973). Social Justice and the city. Baltimore: John Hopkins University press.

Herce, M. (2005). Urbanización, precios del suelo y modelo territorial: la evolución reciente del área metropolitana de Barcelona. Revista EURE, XXXI (93), pp. 35-51. http://dx.doi.org/10.4067/S025071612005009300003

Hernández, F. (2014). Abordaje teórico de la renovación urbana como proceso de transformación en la estructura urbana. Aplicación en el casco histórico de la ciudad de Mendoza, Argentina. Cardinalis, 0(2), 4969. Recuperado de https://revistas.unc.edu.ar/index.php/cardi/article /view/7381

Hernández, R., Fernández C. y Baptista, P. (2014). Metodología de la Investigación. México: Editorial Mc Graw Hill.

Hurtado, M. V. (2011). Análisis de la Renovación Urbana como Estrategia de Recuperación del Centro Histórico de Bogotá: Estudio de Caso Barrio Santa Bárbara colonial (nueva Santa Fe), en el período 1976-2000. Recuperado de http://repository.urosario.edu.co/handle/10336/240 $\underline{6}$

Instituto Nacional de Estadística, Geografía e Informática [INEGI] (2010a). Censo de población y vivienda. Principales resultados por localidad ITER (2010). Recuperado de: http://www.inegi.org.mx/est/contenidos/proyectos/c cpv/cpv2010/iter 2010.aspx

Instituto Nacional de Estadística, Geografía e Informática [INEGI] (2010b). Sistema para la Consulta de Información Censal (SCINCE).
Instituto Nacional de Estadística de Geografía e informática [INEGI] (2015). Encuesta intercensal. Recuperado de https://www.inegi.org.mx/programas/intercensal/20 $15 /$

Instituto Nacional de Estadística, Geografía e Informática [INEGI] (2016). Inventario Nacional de Viviendas 2016. Recuperado de http://www.beta.inegi.org.mx/app/mapa/inv/

Jaramillo, S. (2003). Los fundamentos económicos de la participación en plusvalías. Los Andes: CIDE.

Kanai, M. \& Ortega - Alcázar, I. (2009). The prospects for progressive culture-led urban regeneration in Latin America: cases from México City and Buenos Aires. International Journal of Urban and Regional Research, 33(2), 483-501.

Lacarrieu, M., Girola, M., Thomaz, A., Yacovino, M., Lekerman, V. y Crovara, M. (2011). Procesos de recualificación y relegación en la ciudad de Buenos Aires. Repensando la noción de ciudad-fragmento y la despolitización de lo urbano. Revista Argumentos UAM-X, 24(66), 15-35. Recuperado en 11 de diciembre de 2019, de http://www.scielo.org.mx/scielo.php?script=sci artte xt\&pid=S0187-57952011000200002\&lng=es\&tlng=es.

López Morales, E. (2008). Destrucción creativa y explotación de brecha de renta: discutiendo la renovación urbana del peri-centro sur poniente de Santiago de Chile entre 1990 y 2005. Scripta Nova. Revista Electrónica de Geografía y Ciencias Sociales, 12(270). Recuperado de http://www.ub.edu/geocrit/sn/sn-270/sn-270100.htm

Martínez, S. (2004). A gentrification: conceito e método. En A. Alessandri \& C. Cabrera, Urbanizacao e mundializacao, estudios sobre a metrópole. Sao Paulo: LABUR, USP.

Nobre, E. (2002). Urban regeneration experiences in Brazil: historical preservation, tourism development and gentrification in Salvador da Bahia. URBAN DESIGN International, 7, 109-124. http://dx.doi.org/10.1057/palgrave.udi.9000066.

Ormindo de Azevedo, P. (2009). El Centro Histórico de Bahía revisitado. Andamios, 6(12), 95-113. Recuperado en 11 de diciembre de 2019, de http://www.scielo.org.mx/scielo.php?script=sci artte xt\&pid=S1870-00632009000300005\&lng=es\&tlng=es. 
Orozco, ME; Tapia J. (2011). Reserva territorial y construcción social del espacio urbano. Zona metropolitana de Toluca, Estado de México. México: Universidad Autónoma del Estado de México.

Polése, M. (1998). Economía urbana y regional. Costa Rica: LUR

Precedo, A. (1996). Ciudad y Desarrollo Urbano, Madrid, España: Síntesis

Quintana, L. (1999). Búsqueda de pautas y criterios de intervención óptimos para la revitalización urbanística del barrio de San Felipe. El casco viejo de Panamá. Scripta Nova, Revista electrónica de Geografía y Ciencias Sociales, (46). Recuperado de http://www.ub.edu/geocrit/sn-45-6.htm

Redacción (29 de noviembre de 2018). Paseo Molino, viajar de lo histórico a lo contemporáneo. Glocal Design Magazine. Recuperado de https://glocal.mx/paseo-molino/

Revista Centro Urbano (s.f.). Recuperado de https://centrourbano.com/revista/wpcontent/uploads/Paseo-Molino-5-768x432.jpeg

Richardson, H. (1971). Economía del urbanismo. Madrid: Alianza Editorial.

Rodríguez, P. (2007). Mecanismos financieros aplicados en la rehabilitación del centro histórico de La Habana, En F. Carrión (Ed.), Financiamiento de los centros históricos de América Latina y el Caribe, pp. 391-402.. Quito: FLACSO - Lincoln Institute.

Rossi, A. (2013). Arquitectura en la ciudad. Gustavo Gili.

Sánchez López, M. (2000). La rehabilitación de los centros históricos en México: un estado de la cuestión. Biblio 3W, Revista bibliográfica de Geografía y Ciencias Sociales, (215). Recuperado de: http://www.ub.edu/geocrit/b3w-215.htm fecha de descarga: $18 / 4 / 14$

Sánchez, N., \& Orozco Hernández, M. (2013). Ciclo de vida del centro histórico de la ciudad de Toluca, Estado de México. Urbano, 16(27), 67-74. Recuperado a partir de http://revistas.ubiobio.cl/index.php/RU/article/vie $w / 720$

Sandroni, P. (2006). Renovación urbana y gentrificación: evaluación de algunos impactos demográficos, sociales y económicos de la operación urbana Faría Lima en la ciudad de San Pablo. Revista Medio Ambiente y Urbanización, 65(1), 109-110.
Sassen, S. (1991). La ciudad global: Nueva York, Londres, Tokio. Buenos Aires: Eudeba.

Schelotto, S. (2007). Breves trazos sobre el financiamiento del centro histórico de Montevideo. En F. Carrión (Ed.), Financiamiento de los centros históricos de América Latina y el Caribe, pp-381-389. Quito: FLACSO - Lincoln Institute.

Schteingart, M. (2007). Problemas y políticas urbanas en América Latina. Certidumbres y falacias. Estudios Demográficos y Urbanos, 2(3), 717-722. Recuperado de http://www.redalyc.org/articulo.oa?id=3122230

Soja, E. (2004). Seis discursos sobre la post metrópolis. En: Ramos, A. (Ed.) Lo urbano en veinte autores contemporáneos. Barcelona: Ediciones UPC.

Tamarit, L. (2001). El regreso a la ciudad construida. La recuperación de la ciudad. En F. Carrión, La ciudad construida. Urbanismo en América Latina, pp.25-28. Ecuador: Flacso-Rispergraf.

Tapia Blanco, J. (2013). Teorías de estructuración del territorio: y la dimensión subjetiva del espacio. Recuperado de https://es.scribd.com/document/57890423/TEORIASDE-

Valencia, M. (2004). Escuelas y Paradigmas sobre la ciudad moderna. Breve recorrido por los principales discursos del siglo XX. Proyecto de Investigación. CEAUP. 2004-2005. D.T. Nuevos Territorios del pensamiento urbanístico. Santiago de Chile: Centro de Estudios Arquitectónicos, Urbanísticos y del Paisaje, Facultad de Arquitectura, Urbanismo y Paisaje.

Vergara, C. (2013). Gentrificación y renovación urbana. Abordajes conceptuales y expresiones en América Latina. Anales de Geografía, 33(1), 219-234. http://dx.doi.org/10.5209/rev AGUC.2013.v33.n2.43 $\underline{006}$

Vinuesa, T. (1992). Cascos antiguos y cetros históricos; problemas, políticas y dinámicas urbanas. Madrid: Ministerio de Obras Públicas y Transportes.

Vite Pérez, M. (2010). Reflexiones sobre la mercantilización del patrimonio histórico de la Ciudad de México. Biblio 3W Revista Bibliográfica de Geografía y Ciencias Sociales, (882). Recuperado de: http://www.ub.edu/geocrit/b3w-882.htm

Zunino, H. M. (2000). La teoría de la estructuración y los estudios urbanos. ¿Una aproximación innovadora para estudiar la transformación de ciudades? Scripta Nova. Revista Electrónica de Geografía y Ciencias Sociales (69). Recuperado de: http://www.ub.edu/geocrit/sn-69-74.htm 